\title{
Neurochemical evidence of astrocytic and neuronal injury commonly found in COVID-19
}

Nelly Kanberg, MD, Nicholas J. Ashton, PhD, Lars-Magnus Andersson, MD, PhD, Aylin Yilmaz, MD, PhD, Magnus Lindh, MD, PhD, Staffan Nilsson, PhD, Richard W. Price, MD, PhD, Kaj Blennow, MD, PhD, Henrik Zetterberg, MD, PhD, and Magnus Gisslén, MD, PhD

Neurology ${ }^{\circledR}$ 2020;95:e1754-e1759. doi:10.1212/WNL.0000000000010111

\author{
Correspondence \\ Dr. Gisslén \\ magnus.gisslen@infect.gu.se
}

\begin{abstract}
Objective

To test the hypothesis that coronavirus disease 2019 (COVID-19) has an impact on the CNS by measuring plasma biomarkers of CNS injury.

\section{Methods}

We recruited 47 patients with mild $(n=20)$, moderate $(n=9)$, or severe $(n=18)$ COVID-19 and measured 2 plasma biomarkers of CNS injury by single molecule array, neurofilament light chain protein (NfL; a marker of intra-axonal neuronal injury) and glial fibrillary acidic protein (GFAp; a marker of astrocytic activation/injury), in samples collected at presentation and again in a subset after a mean of 11.4 days. Cross-sectional results were compared with results from 33 age-matched controls derived from an independent cohort.
\end{abstract}

\section{Results}

The patients with severe COVID-19 had higher plasma concentrations of GFAp $(p=0.001)$ and NfL $(p<0.001)$ than controls, while GFAp was also increased in patients with moderate disease $(p=0.03)$. In patients with severe disease, an early peak in plasma GFAp decreased on follow-up $(p<0.01)$, while NfL showed a sustained increase from first to last follow-up $(p<$ $0.01)$, perhaps reflecting a sequence of early astrocytic response and more delayed axonal injury.

\section{Conclusion}

We show neurochemical evidence of neuronal injury and glial activation in patients with moderate and severe COVID-19. Further studies are needed to clarify the frequency and nature of COVID-19-related CNS damage and its relation to both clinically defined CNS events such as hypoxic and ischemic events and mechanisms more closely linked to systemic severe acute respiratory syndrome coronavirus 2 infection and consequent immune activation, as well as to evaluate the clinical utility of monitoring plasma NfL and GFAp in the management of this group of patients.

\footnotetext{
From the Department of Infectious Diseases (N.K., L.-M.A., A.Y., M.L., M.G.), Institute of Biomedicine, Sahlgrenska Academy, and Wallenberg Centre for Molecular and Translational Medicine (N.J.A.), University of Gothenburg; Region Västra Götaland (N.K., L.-M.A., A.Y., M.G.), Sahlgrenska University Hospital, Department of Infectious Diseases, Gothenburg; Department of Psychiatry and Neurochemistry (N.J.A., K.B., H.Z.), Institute of Neuroscience \& Physiology, Sahlgrenska Academy at the University of Gothenburg, Mölndal; King's College London (N.J.A.), Institute of Psychiatry, Psychology \& Neuroscience, Maurice Wohl Clinical Neuroscience Institute; NIHR Biomedical Research Centre for Mental Health \& Biomedical Research Unit for Dementia at South London \& Maudsley NHS Foundation, London, UK; Department of Mathematical Sciences (S.N.), Chalmers University of Technology, Gothenburg; Clinical Neurochemistry Laboratory (K.B., H.Z.), Sahlgrenska University Hospital, Mölndal, Sweden; Department of Neurodegenerative Disease (H.Z.), UCL Institute of Neurology, London; UK Dementia Research Institute at UCL (H.Z.), London; and Department of Neurology (R.W.P.), University of California San Francisco.

Go to Neurology.org/N for full disclosures. Funding information and disclosures deemed relevant by the authors, if any, are provided at the end of the article.
} 


\section{Glossary}

CI = confidence interval; COVID-19 = coronavirus disease 2019; GFAp = glial fibrillary acidic protein; ICU = intensive care unit; IQR = interquartile range; NfL = neurofilament light chain protein; RdRP = RNA-dependent RNA polymerase; SARS$\mathrm{CoV}=$ severe acute respiratory syndrome coronavirus; SARS-CoV-2 = severe acute respiratory syndrome coronavirus 2.

Early in the severe acute respiratory syndrome coronavirus 2 (SARS-CoV-2) outbreak, a case series from Wuhan, China, reported CNS involvement in $36 \%$ of patients hospitalized for severe coronavirus disease 2019 (COVID-19) infection. ${ }^{1}$ CNS involvement was previously described in hospitalized patients infected with severe acute respiratory syndrome coronavirus (SARS-CoV) during the 2003 to 2004 SARS epidemic. ${ }^{2}$ Furthermore, SARS-CoV was isolated from brain tissue with edema and neuronal degeneration at autopsy, confirming viral infection of the neurons. ${ }^{2,3}$ Given the taxonomic similarity between SARS-CoV and SARS-CoV-2, it is plausible that patients with COVID-19 might also exhibit CNS damage related to the infecting coronavirus. It remains unclear to what extent SARS-CoV-2 is able to infect the CNS and, if it does, how the virus reaches the brain, but 2 possible theories have emerged: spread across the cribriform plate of the ethmoid bone in proximity to the olfactory bulb in patients at the early stage of the disease, resulting in the relatively common loss of sense of smell, ${ }^{4}$ or a later-occurring hematogenous spread on the setting of accompanied hypoxia, respiratory, and metabolic acidosis. ${ }^{5}$ Direct CNS infection by SARS-CoV has also been shown in mice, ${ }^{6}$ but whether SARS-CoV-2 infects the brain of humans remains unknown.

To assess the broad impact of COVID-19 on CNS and to test the hypothesis that COVID-19 is accompanied by underappreciated CNS injury, we analyzed 2 plasma biomarkers for CNS injury (glial fibrillary acidic protein [GFAp] and neurofilament light chain protein $[\mathrm{NfL}]$ ) in patients with COVID-19 and matched controls. GFAp is an intermediate filament, is highly expressed in astrocytes, and serves as a marker of astrocytic activation/injury. ${ }^{7} \mathrm{NfL}$ is an intra-axonal structural protein and a biomarker of neuronal injury. ${ }^{8}$ While extensively studied in CSF, recent sensitive methods have shown that plasma measurement of both biomarkers reliably detects CNS injury and correlates with clinical outcomes in a range of conditions. ${ }^{8}$ The aim of this study was to examine the extent of CNS involvement in patients with COVID-19 as indicated by these 2 established biomarkers of CNS disease diagnosis and progression.

\section{Methods}

\section{Study population}

Forty-seven patients with confirmed COVID-19 were divided into 3 groups related to systemic disease severity: 20 patients with mild (i.e., not requiring hospitalization), 9 with moderate (hospitalized and requiring oxygen supplementation), and 18 with severe (admitted to the intensive care unit [ICU] and placed on mechanical ventilation $[\mathrm{n}=17]$ or not considered a candidate for ICU treatment and with fatal outcome $[\mathrm{n}=1]$ ) disease. The biomarker findings were compared to those of age-matched controls $(n=33)$ who were initially recruited as cognitively unimpaired controls for an observational study on risk factors for neurodegeneration. None of them had psychiatric or neurologic comorbidity, and any MRI abnormalities were set as an exclusion criterion.

Blood samples were collected from a subgroup of patients at a mean (SD) of 13.0 (7.37) days after onset of symptoms (16.0 [9.85] days in mild, 11.6 [2.19] days in moderate, and 10.4 [4.35] days in severe disease). In 31 of the patients, follow-up specimens were collected up to a mean (SD) of 11.4 (5.06) days after the first sampling. Follow-up samples on patients with severe COVID-19 were collected during ongoing ICU hospitalization.

\section{Viral diagnostic methods}

The diagnosis of SARS-CoV-2 infection was confirmed with real-time PCR analysis of nasal and throat swab specimens. Nucleic acid was extracted from clinical samples in a MagNA Pure 96 instrument using the Total Nucleic Acid isolation kit (Roche, Basel, Switzerland). Real-time PCR targeting the RNA-dependent RNA polymerase (RdRP) region was performed in a QuantStudio 6 instrument (Applied Biosystems, Foster City, CA) using the probe described elsewhere and the primers RdRP_Fi, GTCATGTGTGGCGGTTCACT and RdRP_Ri, CAACACTATTAGCATAAGCAGTTGT. ${ }^{9}$

\section{Biomarker analyses}

All plasma GFAp and NfL measurements were performed in the Clinical Neurochemistry Laboratory at the Sahlgrenska University Hospital by board-certified laboratory technicians blinded to clinical data using commercially available single molecule array assays on an HD-X Analyzer (Human Neurology 4-Plex A assay (N4PA advantage kit, 102,153), as described by the manufacturer (Quanterix, Billerica, MA). A single batch of reagents was used; intra-assay coefficients of variation were $<10 \%$ for all analytes. Because in acute brain injury plasma GFAp increases rapidly and has a short half-life of 24 to 48 hours while plasma NfL increases later and remains elevated for $>10$ days, ${ }^{10}$ for patients with multiple sampling available, we used the first sample for GFAp and the last for NfL in cross-sectional comparisons between groups.

\section{Statistical analyses}

All data are reported as mean and SD unless otherwise indicated. Associations were measured with the Pearson correlation. Estimated geometric means at 70 years of age were 
compared between the 3 COVID-19 groups and controls by analyzing $\log 10$ plasma levels with analysis of covariance with adjustment for age and including interactions between age and group. Changes in log concentrations from the first to last measure were analyzed with paired $t$ tests. A value of $p<0.05$ was considered significant. Analyses results and graphs were generated with SPSS statistics (IBM SPSS version 25, Chicago, IL) or Prism (GraphPad Software version 8.00, La Jolla, CA).

\section{Standard protocol approvals, registrations, and patient consents}

This study was approved by the Swedish Ethical Review Authority (2020-01771). All participants provided informed consent. For those with severe COVID-19, consent was obtained before they were placed on mechanical ventilation; they were deemed fully capable of understanding the nature of the study and their part in it.

\section{Data availability}

Researchers can apply for access to anonymized data from the present study for well-defined research questions that are in line with the overall research agenda for the cohort. Please contact the corresponding author.

\section{Results}

\section{Demographics}

All patients had a confirmed SARS-CoV-2 infection. Those in the mild group were generally younger and otherwise healthy, while the moderate and severe patients were mostly men, were older, and had more comorbid conditions (table 1). The control group consisted of 16 women and 17 men with a median (interquartile range $[\mathrm{IQR}]$ ) age of $67.0(42.3-77.8)$ years.
Four patients had symptoms of confusion before admission to the ICU, and 1 patient had a single episode of seizure before transfer to the ICU with no signs of epileptic activity at EEG performed the day after. CT scans were normal in 2 of the 3 cases scanned; the third had signs of small vessel disease. MRI scans were not performed due to restrictions imposed by the protection of hospital workers and other patients in place at the time. No additional neurologic abnormalities were documented.

\section{Biomarkers}

Both plasma GFAp $(r=0.62, p<0.001)$ and NfL $(r=0.62, p<$ $0.001)$ were correlated with age for patients with COVID-19 and controls (figure 1, A and B). Concentrations of GFAp and $\mathrm{NfL}$ in the different subgroups are given in table 2. Patients with severe COVID-19 had significantly higher plasma concentrations of GFAp $(p=0.001)$ and NfL $(p<0.001)$ than controls; GFAp was increased also in patients with moderate disease $(p=0.03$, figure $1, \mathrm{~A}$ and $\mathrm{B})$. Patients with severe COVID-19 had $78 \%$ (95\% confidence interval [CI] $27 \%-150 \%)$ higher plasma concentrations of GFAp ( $p=$ $0.001)$ and $208 \%$ (95\% CI 120\%-329\%) higher NfL ( $p<$ $0.001)$ than controls when the estimated geometric means at 70 years of age were compared. Plasma GFAp was 56\% (95\% CI 4\%-133\%) higher in patients with moderate disease compared to controls $(p=0.03)$. A correlation was found between plasma GFAp and NfL $(r=0.580, p<0.001$, figure 1C).

Neither plasma GFAp, nor NfL changed significantly from the initial to the last follow-up in patients with mild or moderate disease (figure 2, A and C). In contrast, in the severe group, plasma GFAp decreased from a median of 215 (IQR $106-281) \mathrm{pg} / \mathrm{mL}$ at the initial to 103 (IQR $60-225) \mathrm{pg} / \mathrm{mL}$ at the last sampling $(p=0.004$, figure $2 \mathrm{~B})$, and plasma $\mathrm{NfL}$

Table 1 Patient characteristics

\begin{tabular}{|c|c|c|c|c|}
\hline & Total $(n=47)$ & Mild $(n=20)$ & Moderate $(n=9)$ & Severe $(n=18)$ \\
\hline \multicolumn{5}{|l|}{ Demographic characteristics } \\
\hline Age, median (IQR), y & $57.8(48.0-69.5)$ & $55.6(37.4-60.2)$ & $67.5(55.4-72.6)$ & $58.0(51.3-72.2)$ \\
\hline \multicolumn{5}{|l|}{ Sex, n (\%) } \\
\hline Female & $15(32)$ & $10(50)$ & $3(33)$ & $2(11)$ \\
\hline Male & $32(68)$ & $10(50)$ & $6(67)$ & $16(89)$ \\
\hline \multicolumn{5}{|l|}{ Comorbid conditions, n (\%) } \\
\hline Any & $18(38)$ & $1(5)$ & $5(56)$ & $12(67)$ \\
\hline Hypertension & $12(26)$ & 0 & $2(22)$ & $10(56)$ \\
\hline Obesity & $3(6)$ & 0 & $1(11)$ & $2(11)$ \\
\hline Diabetes mellitus & $9(19)$ & 0 & $2(22)$ & 7 (39) \\
\hline Coronary heart disease & $7(15)$ & $1(5)$ & $2(22)$ & $4(22)$ \\
\hline Malignancy & $1(2)$ & 0 & 0 & $1(6)$ \\
\hline
\end{tabular}

Abbreviation: $I Q R$ = interquartile range. 
Figure 1 Plasma concentrations of blood-based CNS biomarkers in patients with mild, moderate, and severe COVID-19 compared to healthy controls

A

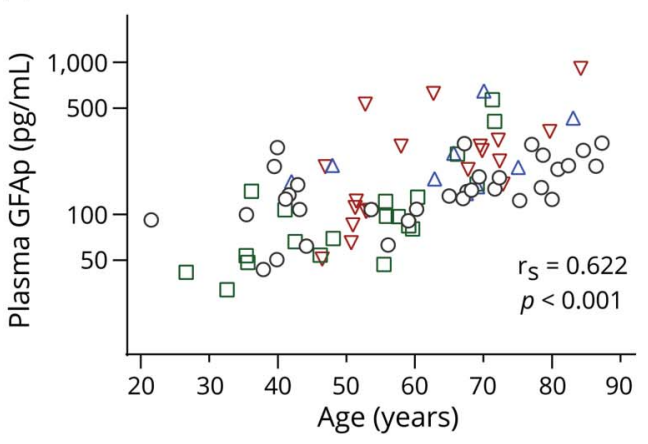

C



B

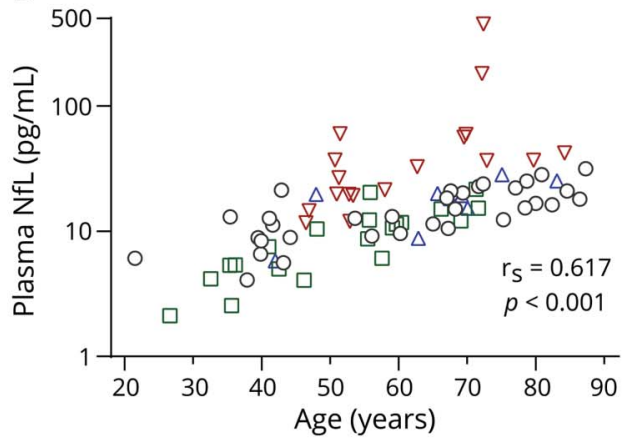

o Controls

$\square$ Mild

$\triangle$ Moderate

$\nabla$ Severe
(A and B) Log10 plasma levels were analyzed with analysis of $\mathrm{CO}^{-}$ variance, including interactions between age and group. Estimated geometric means at 70 years of age for the 3 coronavirus disease 2019 (COVID-19) groups were compared with controls. (A) Age and plasma glial fibrillary acidic protein (GFAp) were significantly correlated. Plasma levels of GFAp were significantly increased in the moderate and severe COVID-19 groups compared to controls ( $p=$ 0.03 and $p=0.001$, respectively). (B) Age and plasma neurofilament light chain protein (NfL) were significantly correlated. Plasma levels of $\mathrm{NfL}$ were 3.1 times higher in patients with severe COVID-19 compared to controls $(p<0.001)$. (C) Correlation between log10 values of plasma GFAp and NfL in patients with COVID-19. concentrations increased from a median of 20 (IQR 11-24) $\mathrm{pg} / \mathrm{mL}$ in the first to 32 (IQR $16-60) \mathrm{pg} / \mathrm{mL}$ in last specimen $(p=0.002$, figure $2 \mathrm{D})$.

Plasma NfL concentration correlated inversely with the blood lymphocyte count, a negative prognostic factor ${ }^{11}(r=$ $-0.37, p=0.047$ ); there was no significant correlation with C-reactive protein concentrations (data not shown).

\section{Discussion}

We have examined 2 blood-based biomarkers for CNS injury in patients with COVID-19. NfL and GFAp have historically been proven to be useful measures of CNS injury when assessed in CSF, but sampling of this fluid is challenging in the clinical COVID-19 setting. In contrast, measurement of these markers in the plasma is convenient and provides a practical method of assessing the effect of COVID-19 on the CNS. This approach follows extensive validation of their ability to detect CNS injury in several conditions, including neurodegenerative disorders, multiple sclerosis, HIV, and cardiac arrest. ${ }^{12-15}$

The results of this study indicate that astrocytic activation/ injury (GFAp measurements) may be a common feature in moderate and severe stages of COVID-19, while neuronal injury (NfL) occurs later in the disease process and mainly in patients with severe disease. One may hypothesize that astrocytic activation/injury is a first response to CNS insult and that a plasma NfL increase reflects a progression to neuronal injury in severe cases.

The pathogenesis of these CNS effects of COVID-19 is not known, although direct invasion of the virus may be unlikely. The entry of SARS-CoV-2 into human host cells is mediated mainly by the cellular receptor angiotensin-converting enzyme

Table 2 Median (IQR) plasma concentrations of GFAp and NfL in different subgroups of COVID-19 and controls

\begin{tabular}{lllll}
\hline & Mild $(\mathrm{n}=\mathbf{2 0})$ & Moderate $(\mathrm{n}=\mathbf{9})$ & Severe $(\mathrm{n}=\mathbf{1 8})$ & Controls $(\mathrm{n}=\mathbf{3 3})$ \\
\hline Plasma GFAp concentrations, median (IQR), pg/mL & $90.5(53.5-139)$ & $204(158-341)$ & $206(106-308)$ & $141(108-207)$ \\
\hline Plasma NfL concentrations, median (IQR), pg/mL & $9.5(5.1-12.2)$ & $19.3(12.1-22.6)$ & $32.7(19.3-56.3)$ & $13.1(9.4-21.0)$ \\
\hline
\end{tabular}

Abbreviations: COVID-19 = coronavirus disease 2019; GFAp = glial fibrillary acidic protein; IQR = interquartile range; NfL = neurofilament light chain protein. 

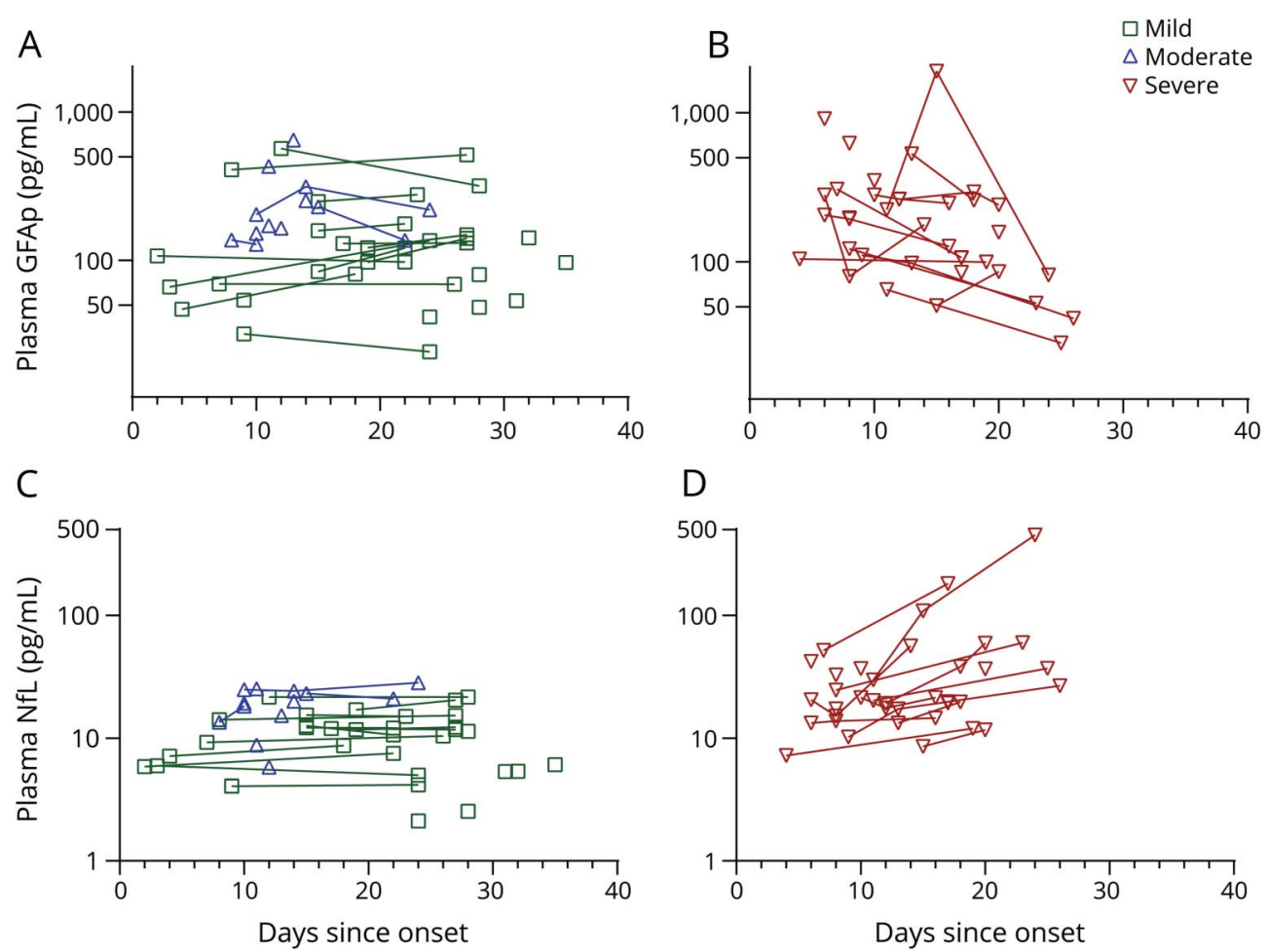

Plasma glial fibrillary acidic protein (GFAp) and neurofilament light chain protein (NfL) concentrations in patients with mild (green squares), moderate (blue triangles), and severe (red triangles) coronavirus disease 2019 (COVID-

19). Lines connect multiple sampling in individual patients. (A and C) No significant changes from initial to last follow-up were found in mild or moderate disease. ( $B$ and D) In contrast, a significant decrease in plasma GFAp $(p=0.004)$ and increase in plasma NfL $(p=$ 0.002) were found in severe COVID-19.

2, which is expressed at very low levels in the CNS under normal conditions. ${ }^{3}$ CNS hypoxia due to respiratory failure caused by COVID-19, thrombotic microangiopathy, and an indirect effect of the vigorous inflammatory response with extensive cytokine activation that is commonly found in severe COVID-19 are more probable explanations, although further study is needed to examine these factors.

Our study has several limitations. First, it included a limited number of participants. Second, due to restrictions imposed to isolate and protect personnel and equipment and because all our severely ill patients were admitted to the ICU and on mechanical ventilators, a thorough neurologic and cognitive evaluation was not done, and long-term follow-ups were limited. In addition, fully accounting for the potential impact of confounding factors such as vascular risk factors has not been possible. None of the controls had any inadequately treated condition, but data on treated comorbid conditions are lacking.

Our results show that plasma biomarkers of CNS damage are increased in patients with COVID-19 and are associated with disease severity. Further studies are needed to clarify the nature of CNS injury in this setting and to further evaluate the utility of these biomarkers in COVID-19.

\section{Study funding}

Supported by the Swedish State Support for Clinical Research (ALFGBG-717531, ALFGBG-720931 and ALFGBG-715986). H.Z. is a Wallenberg Scholar.

\section{Disclosure}

N. Kanberg, N. Ashton, L.-M. Andersson, A. Yilmaz, M. Lindh, S. Nilsson, and R. Price report no disclosures relevant to the manuscript. K. Blennow has served as a consultant or at advisory boards for Abcam, Axon, Biogen, Lilly, MagQu, Novartis, and Roche Diagnostics and is a cofounder of Brain Biomarker Solutions in Gothenburg AB, which is a part of the GU Ventures Incubator Program. H. Zetterberg has served at scientific advisory boards for Denali, Roche Diagnostics, Wave, Samumed, and $\operatorname{CogRx}$; has given lectures in symposia sponsored by Fujirebio, Alzecure, and Biogen; and is a cofounder of Brain Biomarker Solutions in Gothenburg AB, which is a part of the GU Ventures Incubator Program. M. Gisslén reports no disclosures relevant to the manuscript. Go to Neurology.org/N for full disclosures.

\section{Publication history}

Received by Neurology May 5, 2020. Accepted in final form June 4, 2020.

Appendix Authors

\begin{tabular}{lll}
\hline Name & Location & Contribution \\
\hline Nelly & Department of Infectious & Manuscript writing and \\
Kanberg, MD & $\begin{array}{l}\text { Diseases, Institute of } \\
\text { Biomedicine, Sahlgrenska } \\
\text { Academy, University of } \\
\text { Gothenburg, Gothenburg, } \\
\text { Sweden }\end{array}$ & \\
& and interpretation \\
& & \\
\hline
\end{tabular}


Appendix (continued)

\begin{tabular}{|c|c|c|}
\hline Name & Location & Contribution \\
\hline $\begin{array}{l}\text { Nicholas J. } \\
\text { Ashton, PhD }\end{array}$ & $\begin{array}{l}\text { Department of Psychiatry } \\
\text { and Neurochemistry, } \\
\text { Institute of Neuroscience \& } \\
\text { Physiology, Sahlgrenska } \\
\text { Academy at the University of } \\
\text { Gothenburg, Mölndal, } \\
\text { Sweden }\end{array}$ & $\begin{array}{l}\text { Data acquisition and } \\
\text { manuscript revision }\end{array}$ \\
\hline $\begin{array}{l}\text { Lars-Magnus } \\
\text { Andersson, } \\
\text { MD, PhD }\end{array}$ & $\begin{array}{l}\text { Department of Infectious } \\
\text { Diseases, Institute of } \\
\text { Biomedicine, Sahlgrenska } \\
\text { Academy, University of } \\
\text { Gothenburg, Sweden }\end{array}$ & $\begin{array}{l}\text { Patient recruitment and } \\
\text { manuscript revision }\end{array}$ \\
\hline $\begin{array}{l}\text { Aylin Yilmaz, } \\
\text { MD, PhD }\end{array}$ & $\begin{array}{l}\text { Department of Infectious } \\
\text { Diseases, Institute of } \\
\text { Biomedicine, Sahlgrenska } \\
\text { Academy, University of } \\
\text { Gothenburg, Sweden }\end{array}$ & $\begin{array}{l}\text { Patient recruitment and } \\
\text { manuscript revision }\end{array}$ \\
\hline $\begin{array}{l}\text { Magnus } \\
\text { Lindh, MD, } \\
\text { PhD }\end{array}$ & $\begin{array}{l}\text { Department of Infectious } \\
\text { Diseases, Institute of } \\
\text { Biomedicine, Sahlgrenska } \\
\text { Academy, University of } \\
\text { Gothenburg, Sweden }\end{array}$ & $\begin{array}{l}\text { Data acquisition and } \\
\text { manuscript revision }\end{array}$ \\
\hline $\begin{array}{l}\text { Staffan } \\
\text { Nilsson, PhD }\end{array}$ & $\begin{array}{l}\text { Department of } \\
\text { Mathematical Sciences, } \\
\text { Chalmers University of } \\
\text { Technology, Gothenburg, } \\
\text { Sweden }\end{array}$ & $\begin{array}{l}\text { Statistical advice and } \\
\text { analysis }\end{array}$ \\
\hline $\begin{array}{l}\text { Richard W. } \\
\text { Price, MD, } \\
\text { PhD }\end{array}$ & $\begin{array}{l}\text { Department of Neurology, } \\
\text { University of California San } \\
\text { Francisco }\end{array}$ & $\begin{array}{l}\text { Data interpretation and } \\
\text { manuscript revision }\end{array}$ \\
\hline $\begin{array}{l}\text { Kaj Blennow, } \\
\text { MD, PhD }\end{array}$ & $\begin{array}{l}\text { Department of Psychiatry } \\
\text { and Neurochemistry, } \\
\text { Institute of Neuroscience \& } \\
\text { Physiology, Sahlgrenska } \\
\text { Academy at the University of } \\
\text { Gothenburg, Mölndal, } \\
\text { Sweden }\end{array}$ & $\begin{array}{l}\text { Data acquisition and } \\
\text { interpretation \& } \\
\text { manuscript revision }\end{array}$ \\
\hline $\begin{array}{l}\text { Henrik } \\
\text { Zetterberg, } \\
\text { MD, PhD }\end{array}$ & $\begin{array}{l}\text { Department of Psychiatry } \\
\text { and Neurochemistry, } \\
\text { Institute of Neuroscience \& } \\
\text { Physiology, Sahlgrenska } \\
\text { Academy at the University of } \\
\text { Gothenburg, Mölndal, } \\
\text { Sweden }\end{array}$ & $\begin{array}{l}\text { Study concept and } \\
\text { design, data analysis and } \\
\text { interpretation, } \\
\text { manuscript revision }\end{array}$ \\
\hline
\end{tabular}

Appendix (continued)

\begin{tabular}{|c|c|c|}
\hline Name & Location & Contribution \\
\hline $\begin{array}{l}\text { Magnus } \\
\text { Gisslén, MD, } \\
\text { PhD }\end{array}$ & $\begin{array}{l}\text { Department of Infectious } \\
\text { Diseases, Institute of } \\
\text { Biomedicine, Sahlgrenska } \\
\text { Academy, University of } \\
\text { Gothenburg, Sweden }\end{array}$ & $\begin{array}{l}\text { Study concept } \\
\text { and design, } \\
\text { patient recruitment, } \\
\text { data analysis } \\
\text { and interpretation, } \\
\text { manuscript } \\
\text { revision, study } \\
\text { supervision }\end{array}$ \\
\hline
\end{tabular}

\section{References}

1. Mao L, Jin H, Wang M, et al. Neurologic manifestations of hospitalized patients with coronavirus disease 2019 in Wuhan, China. JAMA Neurol Epub 2020 Apr 10

2. Xu J, Zhong S, Liu J, et al. Detection of severe acute respiratory syndrome coronavirus in the brain: potential role of the chemokine mig in pathogenesis. Clin Infect Dis 2005;41:1089-1096

3. Xia H, Lazartigues E. Angiotensin-converting enzyme 2 in the brain: properties and future directions. J Neurochem 2008;107:1482-1494.

4. Baig AM, Khan NA. Novel chemotherapeutic strategies in the management of primary amoebic meningoencephalitis due to Naegleria fowleri. CNS Neurosci Ther 2014;20:289-290.

5. Baig AM. Neurological manifestations in COVID-19 caused by SARS-CoV-2. CNS Neurosci Ther 2020;26:499-510.

6. Netland J, Meyerholz DK, Moore S, Cassell M, Perlman S. Severe acute respiratory syndrome coronavirus infection causes neuronal death in the absence of encephalitis in mice transgenic for human ACE2. J Virol 2008;82:7264-7275.

7. McMahon PJ, Panczykowski DM, Yue JK, et al. Measurement of the glial fibrillary acidic protein and its breakdown products GFAP-BDP biomarker for the detection of traumatic brain injury compared to computed tomography and magnetic resonance imaging. J Neurotrauma 2015;32:527-533.

8. Zetterberg $\mathrm{H}$, Blennow K. Fluid biomarkers for mild traumatic brain injury and related conditions. Nat Rev Neurol 2016;12:563-574

9. Corman VM, Landt O, Kaiser M, et al. Detection of 2019 novel coronavirus (2019$\mathrm{nCoV}$ ) by real-time RT-PCR. Euro Surveill 2020;25:2000045

10. Thelin EP, Zeiler FA, Ercole A, et al. Serial sampling of serum protein biomarkers for monitoring human traumatic brain injury dynamics: a systematic review. Front Neurol 2017;8:300.

11. Zhou F, Yu T, Du R, et al. Clinical course and risk factors for mortality of adult inpatients with COVID-19 in Wuhan, China: a retrospective cohort study. Lancet 2020;395:1054-1062.

12. Gisslen M, Price RW, Andreasson U, et al. Plasma concentration of the neurofilament light protein (NFL) is a biomarker of CNS injury in HIV infection: a cross-sectional study. EBioMedicine 2016;3:135-140.

13. Moseby-Knappe M, Mattsson N, Nielsen N, et al. Serum neurofilament light chain for prognosis of outcome after cardiac arrest. JAMA Neurol 2019;76:64-71.

14. Disanto G, Barro C, Benkert P, et al. Serum neurofilament light: a biomarker of neuronal damage in multiple sclerosis. Ann Neurol 2017;81:857-870.

15. Olsson B, Lautner R, Andreasson U, et al. CSF and blood biomarkers for the diagnosis of Alzheimer's disease: a systematic review and meta-analysis. Lancet Neurol 2016;15: 673-684 


\section{Neurology}

\section{Neurochemical evidence of astrocytic and neuronal injury commonly found in COVID-19}

Nelly Kanberg, Nicholas J. Ashton, Lars-Magnus Andersson, et al. Neurology 2020;95; e1754-e1759 Published Online before print June 16, 2020

DOI 10.1212/WNL.0000000000010111

This information is current as of June 16, 2020

\section{Updated Information \&} Services

References

Citations

Permissions \& Licensing

Reprints including high resolution figures, can be found at: http://n.neurology.org/content/95/12/e1754.full

This article cites 14 articles, 1 of which you can access for free at: http://n.neurology.org/content/95/12/e1754.full\#ref-list-1

This article has been cited by 2 HighWire-hosted articles: http://n.neurology.org/content/95/12/e1754.full\#\#otherarticles

Information about reproducing this article in parts (figures,tables) or in its entirety can be found online at:

http://www.neurology.org/about/about_the_journal\#permissions

Information about ordering reprints can be found online:

http://n.neurology.org/subscribers/advertise

Neurology ${ }^{\circledR}$ is the official journal of the American Academy of Neurology. Published continuously since 1951, it is now a weekly with 48 issues per year. Copyright @ 2020 American Academy of Neurology. All rights reserved. Print ISSN: 0028-3878. Online ISSN: 1526-632X.



